\title{
ESTUDO SOBRE A EVENTUAL AÇÃO DA ARTEMISININA NA INFECÇÃO EXPERIMENTAL DE CAMUNDONGOS PELO TOXOPLASMA GONDII
}

\author{
Vicente Amato Neto, Lucia Maria Almeida Braz, Rubens Campos, Pedro \\ Luiz Silva Pinto, Antonio Augusto Baillot Moreira, \\ Marcos Boulos e Maria Cristina Nahkle
}

\begin{abstract}
Em virtude da conveniência de tentar aprimorar o tratamento da toxoplasmose, de semelhanças taxonômicas e de informes contidos na literatura científica, foi considerado oportuno verificar se a artemisinina, medicamento eficiente no sentido de poder debelar a malária, é ativa na infecção experimental de camundongos pelo Toxoplasma gondii. Houve, entäo, administração de diferentes quantidades desse antiparasitário, inclusive após prévio contato in vitro com toxoplasmas e estimulação da produção de macrófagos, para observações diversificadas a propósito da intenção referida. Pelo menos de acordo com a metodologia usada, a artemisinina não se mostrou eficaz e sugestões para prosseguimento de avaliações acerca do assunto ficaram consignadas.
\end{abstract}

Palavras-chaves: Toxoplasma gondii. Infecção experimental de camundongos. Artemisinina. Tratamento.

A artemisinina é medicamento antimalárico que, conforme avaliações científicas e assistenciais que vêm tendo lugar nos últimos anos, representa recurso dotado de expressivo valor. Hoje sintetizado, esse fármaco derivou da Medicina popular da China e, mais precisamente da planta denominada Artemisia annua L. ou quinghaosu, há centenas de anos considerada valiosa no tratamento da infecção por plasmódios. É esquizonticida e admite-se que atua na sintese protéica $^{34811}$.

Temos nos preocupado sistematicamente com questões referentes à terapêutica de doenças parasitárias e, por isso, consideramos válido verificar se o remédio citado tem a capacidade de debelar o parasitismo devido ao Toxoplasma gondii, uma vez que esse protozoário possui afinidade taxonômica com os agentes causais da

\footnotetext{
Laboratório de Investigação Médica-Parasitologia e Departamento de Doenças Infecciosas e Parasitárias do Hospital das Clínicas da Faculdade de Medicina da Universidade de São Paulo, São Paulo, SP.

Instituto de Medicina Tropical de São Paulo.

Endereço para correspondência: Prof. Vicente Amato Neto. Laboratório de Investigação MédicaParasitologia/HC/FM/USP. Av. Dr. Arnaldo 455, 01245 São Paulo, SP, Brasil.

Recebido para publicação em 16/01/91.
}

malária. Convém aduzir que enfrentamos a toxoplasmose, atualmente, com antibióticos e quimioterápicos eficazes, mas é lícito almejar, a propósito, aprimoramento, sobretudo relacionados como os períodos de administração e efeitos adversos. Ainda mais, não podemos esquecer que essa parasitose é um dos mais importantes processos oportunísticos no âmbito da síndrome da imunodeficiência adquirida (AIDS), cada vez mais disseminada e preocupante.

Quanto à nossa intenção, efetuamos observações utilizando modelo experimental, baseado na infecção de camundongos pelo $T$. gondii.

\section{MATERIAL E MÉTODOS}

Os procedimentos que usamos encontramse a seguir especificados. Empreendemos o estudo através de três modalidades de verificações: I) administração de doses diversas de artemisinina; II) prévio contato da droga, in vitro, com o protozoário; III) aplicação do antiparasitário após estímulo para produção de macrófagos, pois Chang e cols ${ }^{2}$ mencionaram que a atividade de lactóis obtidos do fármaco manifesta-se essencialmente contra formas intracelulares, das quais, então, procuramos contar com maiores contigentes 10 . 
Amato Neto V, Braz LMA, Campos R, Pinto PLS, Moreira AAB, Boulos $M$, Nahkle MC. Estudo sobre a eventual ação da artemisinina na infeç̧ão experimental de camundongos pelo Toxoplasma gondii. Revista da Sociedade Brasileira de Medicina Tropical 24:141-143, jul-set, 1991

- Artemisinina: do produto injetável Artemether (Kunming Pharmaceutical Factory; China) que no impresso que o acompanha inclui subsídios valiosos para escolhermos as doses; junção a óleo de amendoin, para estabelecer em 0,05 ou $0,1 \mathrm{ml}$ as dosagens empregadas.

- Camundongos: Balb-C, fêmeas, com aproximadamente $20 \mathrm{~g}$ de peso e cedidos pelo biotério da Faculdade de Medicina da Universidade de São Paulo.

- Infecção dos animais: cepa "N" do $T$. gondii, mantida por meio de repiques sucessivos, no laboratório onde executamos a pesquisa; quantificação, em câmara de Neubauer, a fim de que em $0,1 \mathrm{mI}$ de solução físiológica estivessem $10^{6}$ taquizoítos, correspondentes ao inóculo para cada roedor; via intraperitoneal.

- Fase I: cinco grupos, dois camundongos em cada um deles; injeção de artemisinina pela via subcutânea, uma vez ao dia, 24 horas após a introdução do inóculo; duração do período de administração: cinco dias; A1: $20 \mathrm{mg} / \mathrm{kg} / \mathrm{dia} ; \mathrm{A} 2$ : $50 \mathrm{mg} / \mathrm{kg} / \mathrm{dia} ;$ A3: $100 \mathrm{mg} / \mathrm{kg} / \mathrm{dia} ;$ A4: controle da infecção, sem emprego do medicamento; A5: controle da maior quantidade do medicamento; sem infecção.

- Fase II: três animais; contato, in vitro, de $0,4,1$ e $2 \mathrm{mg}$ da droga, no óleo, com $10^{6}$ taquizoítos; em tubo de ensaio, o volume permaneceu a $4^{\circ} \mathrm{C}$, no decurso de 24 horas; inoculação, a seguir, pela via intraperitoneal, das quantidades mencionadas, em cada um dos camundongos.

- Fase III : 35 roedores, divididos em sete grupos com cinco; estimulação para a produção de macrófagos, por intermédio de $0,5 \mathrm{ml}$ de proteosepeptona a $10 \%$, dado a cada camundongo, intraperitonealmente; infecção dos animais 48 horas depois, com o inóculo e maneira padrões; injeção $\mathrm{da}$ artemisinina, pela via subcutânea, uma hora antes da introdução dos toxoplasmas (B1), concomitantemente (B2) e uma, duas ou três horas após (B3, B4 e B5); duração do período de administração: um dia; B1, B2, B3, B4 e B5: quantidade única de $100 \mathrm{mg} / \mathrm{kg}$; B6: controle da infecção, sem emprego do medicamento; B7: controle da proteose-peptona, sem infecção.

Para avaliação sempre recorremos ao mesmo critério, representado pela procura do $T$. gondii no exsudato peritoneal, 72 horas posteriormente à penetração do parasita, com subinoculação em um animal, concernente a cada grupo, na nova busca do protozoário, da mesma forma.

\section{RESULTADOS}

O T. gondii foi detectado na generalidade dos exsudatos, indicando portanto ineficácia da artemisinina, levadas em conta as três táticas metodológicas que programamos. Houve boa tolerância à substância sob teste e à proteasepeptona, que de fato influiu na população de macrófagos peritoneais, que de $92.000 / \mathrm{ml}$ passaram a $1.306 .000 / \mathrm{ml}$, em média.

\section{DISCUSSÃO}

Faz parte da estrutura molecular da artemisinina e derivados ponte de peroxigênio, considerada responsável pela capacidade esquizonticida, inclusive quanto às cepas resistentes de plasmódios. Gametócitos, hipnozoítos e esporozoítos não são atingidos e aceita-se que a efetividade depende de rápida inibição da síntese protéica, advindo mudanças morfológicas em membranas.

A propriedade antipalúdica e o já lembrado parentesco taxonômico animaram-nos a planejar a presente pesquisa, sendo que constatações de Chang e cols ${ }^{2}$ reforçaram a validade de tal interesse. Segundo informes comunicados por esses investigadores, compostos quimicamente afins à artemisinina afiguram-se promissores quanto ao tratamento da toxoplasmose, em virtude de efeito quimioterápico, in vitro, sobre culturas de macrófagos e de células Hela parasitadas, justificando isso, provavelmente, o bloqueio da síntese de nucleotídio por parte do protozoário.

Idealizamos conduta calcada em administração do fármaco a camundongos infectados, com e sem prévio contato in vitro nos toxoplasmas, como ainda após intencional aumento da produção de macrófagos e tratamento em momentos desiguais, destinado a prezar o tempo de penetração do parasita, para melhor juízo a 
Amato Neto V, Braz LMA, Campos R, Pinto PLS, Moreira AAB, Boulos M, Nahkle MC. Estudo sobre a eventual ação da artemisinina na infeç̧ão experimental de camundongos pelo Toxoplasma gondii. Revista da Sociedade Brasileira de Medicina Tropical 24:141-143, jul-set, 1991

respeito da influência em formas intracelulares ${ }^{67}$. Adotando esse comportamento, desejamos focalizar nosso intento de acordo com diversificadas abordagens e concluímos que a artemisinina não tem eficácia.

\section{SUMMARY}

Because of taxonomic similarities to previous data found in the literature, and with the aim of improving treatment of toxoplasmosis, we considered it of interest to assay artemisinin, an effective anti-malarial agent, for the treatment of experimental infection in mice by Toxoplasma gondii. Different amounts of the anti-parasitic agent were administered, including after previous contact in vitro with toxoplasma and stimulated macrophage production. With the methodology used artemisinin was not effective. Suggestions for further studies are made.

Key-words: Toxoplasma gondii. Experimental infection in mice. Artemisinin. Therapy:

\section{REFERÊNCIAS BIBLIOGRÁFICAS}

1. Anderson SE, Remington JS. Effect of normal activated human macrophages on Toxoplasma gondii. The Journal of Experimental Medicine 139: 1154-1174, 1974.

2. Chang $\mathrm{HR}$, Jefford $\mathrm{CW}$, Pechère JC. In vitro effects of three new 1,2,4-trioxanes (pentatroxane, thiahexatroxane, and hexatroxanone) on Toxoplasma gondii. Antimicrobial Agents and Chemoterapy 33: 1748-1752, 1989.

3. Chawira AN, Warhurst DC, Robinson BL, Peters $W$. The effect of combinations of qinghaosu (artemisinin) with standard antimalarial drugs in the suppressive treatment of malaria in mice. Transactions of the Royal Society of Tropical Medicine anh Hygiene 81: 554-558, 1987.

4. Gu HM, Warhurst DC, Peters W. Rapid action of qinghaosu and related drugs on incorporation of $\left[{ }^{3} \mathrm{H}\right]$ isoleucine by Plasmodium falciparum in vitro. Biochemical Pharmacology 32: 2463-2466, 1983.

5. Jiang JB, Jacobs G, Liang DS, Aikawa $M$. Qinghaosu-induced changes in the morphology of Plasmodium inui. The American Journal of Tropical Medicine and Hygiene 34: 424-428, 1985.

6. Jones TC, Hirsch JG. The interaction between Toxoplasma gondii and mammalian cells. II. The absence of lysosomal fusion with phagocitic vacuoles containing living parasite. The Journal of Experimental Medicine 136: 1173-1194, 1972.

7. Jones TC, Yeh S, Hirsch JG. The interaction between Toxoplasma gondii and mammalian cells.

I. Mechanism of entry and intracellular fate of parasite. The Journal of Experimental Medicine 136: 1157-1172, 1972.

8. Klayman DL. Qinghaosu (artemisinin): an antimalarial drug from China. Science 228: 1049 1055, 1985.

9. Krungkrai SR, Yuthavong $Y$. The antimalarial action on Plasmodium falciparum of qinghaosu and artesunate in combination with agents which modulate oxidant stress. Transactions of the Royal Society of Tropical Medicine and Hygiene 81: 710-714, 1987.

10. Nichols BA, $O^{\prime}$ Connor GR. Penetration of mouse peritoneal macrophages by the protozoon Toxoplasma gondii. New evidence for active invasion and phagocytosis. Laboratory Investigation 44: 324-335, 1981.

11. Waki S, Gu HM, Zhu MY. Sensitivity of malaria parasites to artemether (qinghaosu derivative) depends on host cell age. Transactions of the Royal Society of Tropical Medicine and Hygiene 81: 913-914, 1987. 